\title{
AGLOMERADOS PERIFÉRICOS: A EXPRESSÃO DA TRADICIONAL POBREZA E DA SEGREGAÇÃO NAS CIDADES BRASILEIRA
}

\author{
Maria da Penha Smarzaro Siqueira ${ }^{1}$
}

\begin{abstract}
Resumo: $O$ artigo discute a problemática da pobreza urbana, com foco na questão socioespacial, em abordagem que traça uma interface entre aspectos articulados a questão do desenvolvimento desigual no ideário da modernização capitalista, que se intensificou nas cidades brasileiras a partir da segunda metade do século XX. O eixo de análise centra-se em um estudo local referenciando a questão da desigualdade aliada à urbanização desigual, que acirraram a segregação/exclusão de uma ampla camada da população, alojada em aglomerações periféricas, precárias e irregulares num amplo quadro de pobreza e complexidade sociespacial no cenário urbano. Em interpretação histórico-sociológica, buscamos reconstruir a trajetória do objeto de estudo em abordagem qualitativa, apoiada em dados quantitativos e uma pesquisa empírica que cruzam as variáveis na contextualização do tema em questão. Nosso estudo situa a Região Metropolitana da Grande Vitória (ES), destacando o município de Vila Velha e o "Aglomerado de Terra Vermelha" como referência de análise sócio-histórica.
\end{abstract}

Palavras-chave: Desenvolvimento desigual. Pobreza Urbana. Segregação/Exclusão.

\section{PERIPHERAL AGGLOMERATE: THE EXPRESSION OF TRADITIONAL POVERTY AND OF SEGREGATION IN BRAZILIAN CITIES}

\begin{abstract}
This paper discusses the problem of urban poverty, focusing on the social-spacial issue, with an approach that draws an interface between the aspects related to the uneven development matter and the ideas of capitalist modernization, which intensified in Brazilian cities from the second half of XX century. The analysis axle is focused in a local study referring to the inequality issue combined with the uneven urbanization, that have incited the segregation/exclusion of a wide range of population, allocated in remote, precarious, and irregular agglomeration in a wide scene of poverty and social-spacial complexity in the urban context. In a sociological-historical interpretation, we seek to rebuild the trajectory of the study object in a qualitative approach, based on quantitative data and empirical research that cross the contextualization variables of the theme in question. Our study situates the Metropolitan Region of Grande Vitoria (ES), pointing out the municipality of Vila Velha and the "Terra Vermelha Cluster" as a reference of social-historical analisis.
\end{abstract}

Key words: Uneven development, Urban poverty, Segregation/Exclusion.

\footnotetext{
${ }^{1}$ Doutora em História Econômica pela USP. Pós-Doutora em Sociologia Urbana (UNL), Portugal, na área de pesquisa de História Econômica, Sociologia e História Urbana. Professora aposentada da Universidade Federal do Espírito Santo, departamento de História. E-mail: penhasiq@ hotmail.com.
} 


\title{
AGLOMERADOS PERIFERICOS: LA EXPRESIÓN DE LA TRADICIONAL POBREZA Y DE LA SEGREGACIÓN EN LAS CIUDADES BRASILEÑAS
}

\begin{abstract}
Resumen: El presente artículo científico pone en discusión la problemática de la pobreza urbana, con foco en la cuestión socioespacial, en uma aproximación al tema que delinea una interfaz entre aspectos articulados a la cuestión del desarrollo del conjunto de concepiones de la modernización capitalista, que se ha intensificado en las urbes brasileñas desde la segunda mitad del siglo XX. El eje de análisis posee su posición central en un estudio a nivel local, que toma como referencial la cuestión de la desigualdad unida paralelamente a una urbanización desigual, que agudizan la segregación/exclusión de una gran parte de la población, albergada em aglomeraciones periféricas, precarias e no reglamentadas, dispuestas en un escenario de pobreza y complejidad socioespacial insertos en el ambiente urbano. En una interpretación historico-sociológica, se busca reconstruir la trayectoria del tema de estudio en un enfoque cualitativo, lastreada en datos cuantitativos y una investigación empírica en que dichas variables se cruzan para la contextualización del tema en estudio. Nuestro estudio sitúa la región metropolitana del Gran Vitória (ES), destacando el municipio de Vila Velha y el "Aglomeración de la Tierra Roja “, como referencia para el análisis socio-histórico.
\end{abstract}

Palabras clave: Desarrollo desigual. Pobreza urbana. Segregación. Exclusión. Urbanización.

\section{Introdução}

Os entendimentos diversos sobre a expansão de periferias e problemas sociourbanos nas cidades brasileiras se inscrevem principalmente na dinâmica da modernização capitalista e da urbanização acelerada que marcaram o processo de desenvolvimento nacional, tendo como marco histórico a segunda metade do século XX. A partir de 1950, o desenvolvimento nacional, pautado na industrialização iniciada em 1930 vai integrar um processo social mais complexo, intensificando a reprodução das atividades industriais no âmbito de um amplo e diversificado mercado de trabalho e de atividades produtivas, formando um mercado nacional, expandindo consumo, impulsionando as relações sociais e ativando a urbanização em um novo contexto socioeconômico e político. Neste quadro de referências, buscamos aprofundar o debate em torno de aspectos articulados à questão da desigualdade, da pobreza e da modernização, através de mudanças assumidas pela capacidade relativa das cidades de se defrontarem com funções sociais geradoras da expansão e da consolidação do capitalismo no Brasil.

Neste trabalho desenvolvemos um debate histórico-sociológico cruzando noções que perpassam pelo entendimento de modernização, de desigualdade e da pobreza. $\mathrm{Na}$ complexidade conceitual destas categorias, retratamos neste texto uma interligação teóricoconceitual, onde a modernização expressa um conceito que abrange um movimento de 
mudanças sociais pelo qual uma sociedade, através de um processo de industrialização/urbanização, torna-se moderna e avança no processo de desenvolvimento.No entendimento clássico de Giddens (1984) a teoria da modernização está diretamente associada ao desenvolvimento da sociedade industrial, onde se relaciona um conjunto de mudanças que interligam os domínios das estruturas econômicas, políticas, sociais e culturais e dos meios de produção de uma sociedade em um sentido amplo.

Em nossa abordagem a noção de modernização enfatiza a questão desenvolvimento versus crescimento econômico associados à ‘modernização' em um único conceito. O foco no desenvolvimento dos subsistemas econômicos não elegeu outros subsistemas importantes para a construção de uma sociedade menos desigual. Esse é o modelo predominante na trajetória do desenvolvimento nacional contemporâneo (BRESSER-PEREIRA, 2008), processo contraditório que apresenta um caráter excludente onde o equilíbrio da organização social move-se para a ação secundária e o processo de desenvolvimento configura-se de forma desigual. Neste contexto, a pobreza é vista como decorrente da desigualdade social e se apresenta em múltiplas configurações (SILVA, 2010). ${ }^{2}$

Situamos o estado do Espírito Santo, como parâmetro de estudo regional, enfatizando as especificidades locais tradicionais e, em particular, o processo tardio de industrialização em relação ao desenvolvimento capitalista nacional. As mudanças marcadas pela emergência de uma nova ordem produtiva em prática a partir dos anos 60, aliadas à dinâmica socioespacial, se fortaleceram centradas na Região Metropolitana da Grande Vitória, que passou a ser o "lócus" concentrador da modernização. Processo que socialmente, na perspectiva de nossa análise, caminhou na contramão do ideário da modernidade, intensificando a fragmentação social e a consequente desigualdade, num quadro acelerado de urbanização desordenada, que acirrou o processo de segregação e de exclusão de uma ampla camada da população no âmbito do projeto modernizador.

No cenário socioespacial da Região Metropolitana da Grande Vitória, privilegiamos como eixo de estudo o município de Vila Velha, com foco no "Aglomerado de Terra

\footnotetext{
${ }^{2}$ Sobre as questões abordadas ver: SOUZA, J. Modernização seletiva: uma reinterpretação do dilema brasileiro. Brasília: UnB. 2000. __. A construção social da subcidadania: para uma sociologia política da modernidade periférica. Belo Horizonte, Ed. UFMG, 2003. HARVEY, David. Espaços de esperança. Loyola: São Paulo, 2004. A produção capitalista do espaço. São Paulo: Annablume, 2005. BRESSER-PEREIRA, Luiz Carlos. Crescimento e desenvolvimento econômico. Rio de Janeiro: Fundação Getúlio Vargas, 2008. OLIVEN, RG. Urbanização e mudança social no Brasil [online]. Rio de Janeiro: Centro Edelstein, 2010. Available from SciELO Book . www.books.scielo.org. SILVA, Maria Ozanira da Silva e. Pobreza, desigualdade e política pública: caracterizando e problematizando a realidade brasileira. Revista Katálysis, Florianóplois, v. 13, n. 2, jul./dez. 2010. TELLES, Vera da Silva. Pobreza e cidadania. São Paulo: Editora 34, 2001. YAZBEK, Maria Carmelita. Classes subalternas e assistência social. 7. ed. São Paulo: Cortez, 2009.
} 
Vermelha"3. A escolha deste aglomerado periférico se justifica pela complexidade social urbana, composta de diversos tipos de ocupações irregulares, dentre as quais, loteamentos e ocupações clandestinas, espelhando as representações da fragmentação e da segregação no cenário urbano municipal.

Em termos metodológicos buscamos reconstruir a trajetória do objeto de estudo em abordagem qualitativa apoiada na pesquisa bibliográfica, documental e empírica em interface com uma abordagem quantitativa numa perspectiva histórico-sociológica. Os dados quantitativos e os resultados da pesquisa empírica se cruzam na análise do tema, em uma triangulação que contribui para uma maior reflexão sobre as variáveis que envolvem as questões do tema estudado ${ }^{4}$.

\section{Desigualdade social e pobreza: expressão tradicional e permanência}

O Brasil, em sua trajetória histórica, apresenta uma desigualdade social constante que, associada à consequente pobreza, se estruturara na sociedade promovida principalmente pelas profundas assimetrias nas relações sociais, com grande expressão para situações de concentração de riquezas em poucos setores sociais e pela pobreza, exclusão e segregação que permanecem atingindo a maioria da população.

Processo que se ampliou e se agravou com novas características a partir da industrialização/expansão do capitalismo. No âmbito da questão social a tradicional desigualdade se desdobrou e se intensificou seguindo as próprias particularidades da conjuntura histórica/estrutural brasileira. Garcia (2003, p. 09) ressalta que "[...]. O Brasil foi fundado sobre o signo da desigualdade, da injustiça, da exclusão [...] onde não predominava nenhuma preocupação com a democracia social, econômica e política”.

No século XX, o que se apresentou foi o agravamento de uma dinâmica já em curso. A ausência de mecanismos para uma melhor distribuição de rendas e para a questão fundiária,

\footnotetext{
${ }^{3}$ As periferias dos aglomerados urbanos caracterizam áreas que concentram extensas regiões com alta densidade populacional. Para definir o espaço urbano como aglomerado metropolitano são empregados indicadores demográficos e econômicos, assim como dos fluxos de bens e serviços. CARVALHO, Carlos Henrique Ribeiro de. Texto para Discussão. Desafios da mobilidade urbana no Brasil. Brasília, IPEA, 2016. Disponível em: http://repositorio.ipea.gov.br. Ver: BRITO, F.; HORTA, C. A urbanização recente no Brasil e as aglomerações metropolitanas. Cedeplar - IUSSP, 2002.

4 Nos campos de pesquisa apoio em BARDIN, Laurence. Análise de conteúdo. Lisboa: 70, 2013. Suportes metodológicos interligados na coleta de dados e suas análises. MINAYO, Maria Cecília de Souza (org.). Pesquisa Social: teoria, método e criatividade. Petrópolis: Vozes, 2008. A pesquisa empírica (entrevistas e aplicação de questionários) abordou entre 10 a 12 pessoas de famílias distintas por bairro, dirigentes das escolas públicas e de posto de saúde. Entrevistas contemplaram em médias 3 pessoas por bairro.
} 
a precariedade na infraestrutura, no saneamento, na saúde, nas condições sociais de trabalho, no acesso e na qualidade da educação vão se unir à expulsão do campo, à urbanização sociopática e aos avanços das contradições do desenvolvimento socioeconômico, constituindo as fontes que multiplicaram os indicadores da desigualdade e da pobreza no Brasil (WANDERLEY, 2010).

No conjunto das mutações econômicas, sociais e políticas que caracterizaram o desenvolvimento nacional, principalmente a partir de 1930, na trajetória do Estado e sua prática social, Sposati (1988, p. 46) aponta que o

[...] modelo estatal paternalista de pré-64, onde o Estado dizia-se o "amparador dos pobres", seguiu-se ao modelo estatal-desenvolvimentista, que se propôs a "corrigir efeitos indesejados do crescimento", entretanto nenhum destes modelos [...]. puseram em questão o que significava a assistência social num Estado democrático e qual seu horizonte.

As ideias de progresso conjugadas à modernização como projeto nacional, não situavam a desigualdade como um entrave à modernidade, nem os mecanismos do modelo modernizador colocavam em pauta questões relativas à problemática social, bem como o enfrentamento concreto frente à pobreza.

O Relatório da Comissão Mista Especial de Combate à Pobreza (1999) apresentou dados expressivos da população brasileira vivendo abaixo da linha da pobreza e da indigência. Uma pobreza intimamente relacionada à desigualdade, que no Brasil se incluía entre as mais altas do mundo. O relatório ainda destaca o grande distanciamento entre o crescimento econômico e os investimentos em políticas sociais, onde o primeiro deveria ter um caráter redistributivo direcionado para políticas sociais mais inclusivas que atingissem de forma concreta as necessidades da população, diminuindo os índices de pobreza e ao mesmo tempo rompendo com sua tradicional persistência. Neste sentido, o Relatório (1999, p. 27) aponta que em tese a política redistributiva e as ações sociais “[...] não têm sido capazes de alterar sequer minimamente, esse quadro explicando porque o grau da pobreza brasileira se apresentava muito superior ao de países com renda similar a nossa", não promovendo a construção de uma sociedade com maior justiça social.

O não reconhecimento da desigualdade como um risco na construção de uma sociedade realmente moderna, comprometia a compreensão de um debate mais universal sobre o desenvolvimento contemporâneo, criando barreiras no entendimento de aspectos mais multidimensionais onde questões sociais, culturais, ambientais e institucionais ganham 
relevância frente à noção predominante relativa ao crescimento econômico. Uma visão mais integrada entre a liberdade, às potencialidades individuais e o papel das distintas instituições, que podem conduzir o desenvolvimento com maior abrangência social e mais direcionado no combate às privações, se coloca como tema emergencial na construção de uma sociedade mais justa (SEN, 2000). No Brasil esse entendimento tradicionalmente se apresenta em uma difícil compreensão, distanciando as possibilidades de sua construção.

A partir do início dos anos 50, os direcionamentos políticos e socioeconômicos, norteados por rumos estruturais mais contemporâneos na dinamização do setor produtivo e no incremento das relações capitalistas, intensificaram o desenvolvimento urbano-industrial, estabelecendo um novo ritmo de crescimento nos centros urbanos, que promoveu a multiplicação das funções da cidade seguindo as necessidades do desenvolvimento econômico, estabelecido em novas bases da reprodução capitalista (DRAIBE, 2004).

Por outro lado, embora o Brasil já tivesse iniciado uma fase de maior desenvolvimento econômico desde 1930, com foco na relação capital-trabalho e formulado a regulação trabalhista, norteada por "[...] uma legislação social que adequasse as relações sociais à nova realidade [...]" Carvalho (2002, p. 46), a política colocada em prática não tinha um caráter de amplitude social. Os rumos da modernização e do desenvolvimento industrial a partir dos anos 30 ampliam a desigualdade no contexto do próprio modelo político-econômico e social que se reestrutura na sociedade brasileira. As alterações que ocorrem na dinâmica da urbanização, com mudanças relativas à hierarquia urbana tradicional e à formulação de modelos mais adequados ao novo quadro socioeconômico do país, mudam o tradicional perfil urbano das cidades num quadro de grandes diferenças sociais.

A rápida concentração da população nas áreas urbanas a partir de 1970 mudou o caráter demográfico no país, quando o Brasil perde a característica de país agrário e ganha o perfil de país urbano. Os dados dos Censos demográficos do IBGE (2010) em 1960, registram 45,1\% da população brasileira concentrada nas cidades; em 1970, a taxa de urbanização passou para $55,9 \%$, marcando um novo tempo na estrutura demográfica nacional. A crescente urbanização da população nas décadas seguintes - 75,5\% em 1991 e 81,2\% em 2000 - demonstra a relevância das mudanças estruturais ocorridas no país no final do século XX. Um processo contínuo e intenso de êxodo rural contribuiu de forma muito significativa para a mudança no padrão 
demográfico e expansão dos aglomerados metropolitanos, sendo a Região Sudeste o maior centro de concentração de população urbana do país ${ }^{5}$.

Face às grandes contradições do processo de desenvolvimento nacional, a desigualdade estabelecida se impõe como um componente natural na sociedade brasileira, onde a modernização/urbanização não foi conceituada, como explica Guldin $(2001)^{6}$ apud. Davis (2006, p. 19), “[...] como transformação estrutural e intensificação da interação de todos os pontos de um contínuo urbano-rural”. Esse movimento contrário deu lugar a formas perversas de não cidadania e que encontrou eco no processo de modernização do país (SOUZA, 2003).

Essa noção sinaliza para uma compreensão maior da naturalidade da pobreza e da desigualdade que ganhou novas roupagens ao longo do século XX. A gravidade deste processo e sua permanecia ao longo deste período, se inscreve num universo social muito amplo e complexo “[...] que se explica por várias situações de privação, onde se inclui pobreza, discriminação, não equidade, não acessibilidade, não representação política” (SPOSATI, 1996, p.13). Na diversidade socioeconômica brasileira a desigualdade se eleva, na medida em que se alargava o distanciamento ao acesso a bens e recursos materiais dos diferentes grupos sociais e o ideal de igualdade e de construção da cidadania, como princípio do desenvolvimento, permaneciam ausentes, dando lugar à reprodução da pobreza como eixo da questão social nacional (IVO, 2008).

A permanente precariedade da inserção dos trabalhadores no mercado de trabalho, bem como os baixos salários, que não garantem a segurança de manutenção digna das necessidades de sobrevivência nos centros urbanos, compõem a conjunção de fatores contribuintes para uma maior reprodução das desigualdades, desvelando a complexidade da questão social. Os novos paradigmas que despontam no decorrer dos anos 90 marcam a nova configuração da questão social, com o enfraquecimento das mediações entre Estado e sociedade e a fragilidade dos vínculos que entrelaçam a prática da cidadania em relação a grupos sociais que povoam o mundo das privações (CASTEL, 2010).

A integração dos vínculos sociais predominantes até o final do século XX muda o sentido quando se redefiniram novas configurações na sociedade capitalista. Múltiplas consequências se delinearam no âmbito da questão social com novas formas de vulnerabilidades que colocam em questão os novos paradigmas gerados pelo projeto

5. Ver: BRITO, F.; HORTA, C. A urbanização recente no Brasil e as aglomerações metropolitanas. Cedeplar/IUSSP. 2002.

6 GULDIN, Gregory. What's a Peasant To Do?: Village Becoming Town in Southern China. Boulder, Westview, 2001. 
modernizador sob a ótica da globalização e de programas neoliberais. Wanderley (2010, p.137), ressalta que persiste uma “[...] questão social ampla, histórica e estrutural, irresolúvel na sua totalidade nos marcos da formação econômico-social do capitalismo realmente existente".

As mudanças ocorridas na dinâmica social redefiniram as características da problemática sociourbana e da pobreza brasileira, colocando em evidência a necessidade de se reavaliar os mecanismos que reproduzem formas de integração social e de vida nas cidades. Trata-se de um processo inacabado, conflituoso e contraditório em ritmo contínuo que supera os limites da tradicional questão social no Brasil.

\section{Contextualização regional: a Grande Vitória e a problemática da desigualdade}

O desenvolvimento industrial que se expandia no Brasil até o início dos anos de 1960, promove mudanças expressivas na economia nacional e na vida urbana das cidades. No Espírito Santo, mesmo estando o Brasil sob a égide de economia industrial avançada, as relações socioeconômicas permaneciam sendo conduzidas pelo setor agrário-exportador cafeeiro, com um setor industrial inexpressivo, ligado à transformação de produtos primários. Embora o Porto de Vitória já atuasse como fator de desenvolvimento regional e nacional e veículo estratégico na afirmação do comércio internacional estadual, o Espírito Santo permanecia à margem do desenvolvimento global do sudeste brasileiro, no sentido da produção e reprodução das atividades socioeconômicas capitalistas. O porto cafeeiro incorpora a diversificação no fluxo exportador com o movimento comercial do minério de ferro, iniciado pela Companhia Vale do Rio Doce (CVRD) a partir de 1940, que promove uma nova dinâmica econômica e espacial no cenário portuário, diante da expansão da nova atividade mercantil que passou a exigir a ampliação do porto e a criação de terminais especializados ${ }^{7}$ (SIQUEIRA, 1994). Modelo alterado nos anos de 1960 quando uma nova política econômica nacional atinge com grande impacto, a estrutura econômica capixaba.

Desestrutura-se um modelo primário-exportador em função de um novo padrão de acumulação - o industrial, apoiado na implantação de Grandes Projetos Industriais ${ }^{8}$. Esse foi o marco da modernização e da expansão das relações capitalistas no Espírito Santo, atreladas a

\footnotetext{
7 Companhia Vale do Rio Doce criada em 1942, Governo de Getúlio Vargas para a exploração do minério fino e grosso na região de Itabira, Minas Gerais. Eixo de transporte inter-regional a Estrada de Ferro Vitória Minas e veículo exportador, o porto de Vitória, em logística integrada ferrovia-porto. Em 2008 mudou o nome Companhia Vale do Rio Doce - CVRD, para VALE. S.A. http://www.cvrd.com.br.

8 Ver: SIQUEIRA, Maria da Penha Smarzaro. Industrialização e empobrecimento urbano: o caso da Grande Vitória.1950-1980. Vitória: Grafitusa, 2010.
} 
um amplo processo de mudanças que alterou o perfil do estado no quadro regional brasileiro enquanto polo de expansão industrial e portuária. Aliada ao novo modelo de desenvolvimento, a urbanização emerge, inicialmente, como condição da consolidação capitalista, para se efetuar, até o final do século XX, em um condicionante deste mesmo processo.

No processo de desenvolvimento nacional, a indústria tornava-se o setor mais dinâmico, transformando o Brasil em uma sociedade urbana moderna seguindo as tendências de um país urbano-industrial. "As cidades, portanto, tornaram-se crescentemente mais importantes como centros dinâmicos da produção e como símbolos ideológicos de desenvolvimento" (OLIVEN, 2010, p. 64). Neste contexto, o trinômio desenvolvimentoindustrialização-urbanização implicou sucessivos e constantes deslocamentos de população das áreas rurais para os centros urbanos, na expectativa de conquistar melhores condições de vida e de trabalho formal. Oliver (2010, p. 65) ainda ressalta que: "Um dado significativo sobre o volume da migração no Brasil é o fato de que por ocasião do censo de 1970 quase um terço de todos os brasileiros estavam vivendo num lugar diferente daquele em que tinham nascido". $\mathrm{O}$ censo demográfico de 1970 registra que 56\% da população brasileira estava nas cidades (IBGE, 1970). O crescente movimento das migrações passou a constituir o elo maior entre as mudanças estruturais pelas quais a sociedade estava passando, aliando o desenvolvimento da economia, a expansão do mercado de trabalho, a intensificação da mão-de-obra trabalhadora e a urbanização.

No Espírito Santo a consolidação do modelo urbano-industrial segue as tendências nacionais, a dinâmica populacional do estado pautada no movimento das migrações deixa para o passado a característica rural incorporando os novos paradigmas urbanos do Brasil. $\mathrm{O}$ complexo industrial centrado na região de Vitória elevou não apenas o ritmo da economia, como também o movimento da urbanização, que tomou forma de aglomeração num crescimento acelerado, gerando a multiplicação dos problemas urbanos. Os direcionamentos da nova lógica do modelo modernizador e a dinâmica do crescimento econômico reproduziram novas formas de distribuição espacial da população, intensificando a ocupação e a expansão do espaço metropolitano. O grande processo de urbanização foi seguido de problemas sociais diretamente interligados à expansão da periferia, à falta de moradias, à favelização, à carência de infraestrutura, ao mercado de trabalho insuficiente, ao crescimento do setor informal, à ocupação de áreas de risco e à violência (SIQUEIRA, 2010).

A mobilidade populacional no Espírito Santo acompanhou o movimento demográfico nacional, com concentração inicial na capital do estado, Vitória, espalhando-se nos municípios 
periféricos da cidade (Viana, Cariacica, Vila Velha e Serra) que formavam junto com a capital a RMV (Região Metropolitana de Vitória) ${ }^{9}$. Em 1960 a população urbana do estado representava $28,4 \%$ na totalidade populacional e a RMV concentrava $13,7 \%$ deste total. Em 1980 a população urbana atinge $64,2 \%$; em $2000,79,6 \%$ com um movimento maior em direção a RMV, que em 1980 abrigava 34,9 desta população; em 2000, 46,6\% (IBGE, 2010).

As articulações do crescimento econômico moderno promoveram uma mudança expressiva na distribuição espacial da população reproduzindo novas alternativas socioeconômicas que contribuíram muito para intensificar a ocupação e a expansão do espaço metropolitano. É nesse contexto que se entrelaça a reprodução, a manutenção e a permanência da desigualdade na Grande Vitória, norteada pela pobreza e pela segregação socioespacial no contexto da desigualdade nacional. As desigualdades socioespaciais nas cidades brasileiras apontavam questões de grande complexidade que se configuravam no universo urbano no “[...] quadro de uma aparente fragmentação que ganhava força no sentido da estruturação social e da estruturação do espaço urbano" (GOUVÊA, 2005, p.29).

A dinâmica sociourbana que vai se delinear nos anos de 1980, reforça a tradicional desigualdade expressa na crescente visibilidade da pobreza e nas áreas de exclusão/segregação dos espaços periféricos das cidades, demarcando novos paradigmas no âmbito da questão social ultrapassando os aspectos da pobreza em suas representações das privações pessoais e de bens materiais. Nesta contextualização situamos a Região Metropolitana de Vitória, com destaque para o município de Vila Velha que concentra, desde 1960, o maior número de bairros da Grande Vitória e a maior concentração populacional e migratória. Neste município centramos nossa pesquisa no Aglomerado de Terra Vermelha, que se consolidou abrigando uma população muito pobre, composta prioritariamente por migrantes e pessoas expulsas de outras áreas carentes locais e das periferias da região metropolitana. De acordo com a organização políticoadministrativa municipal situa-se na Região 5 integrada a Grande Jucu ${ }^{10}$. No mapa 1, acima, identificamos o Aglomerado de Terra de Vermelha na Região 5 do município de Vila Velha.

9. Região Metropolitana da Grande Vitória criada em 1995. LEI COMPLEMENTAR n 58 , de 21 de fevereiro de 1995, Governo do Estado do Espírito Santo. Diário oficial. Alterada em 1999 (Lei Complementar nº 159) inclui o município de Guarapari e novo texto formatado em 2001 (Lei Complementar $n^{\circ} .318$ ) inclui o município de Fundão, constituindo a RMGV com 7 municípios. Consideramos nesta pesquisa os 4 municípios que constituíam a Região Metropolitana de Vitória até 1999. Dados Gerais da RMV. Disponível em: www.vitoria-es-brasil.com. 10 Barra do Jucu. Balneário e antiga vila de pescadores com origens históricas e tradições religiosas e folclóricas (congo é um dos ritmos locais), próxima à foz do Rio Jucu. 
Fronteiras: Revista de História

Aglomerados periféricos: a expressão da tradicional pobreza e da segregação nas cidades brasileiras

Maria da Penha Smarzaro Siqueira

Mapa 1 - Aglomerado de Terra Vermelha

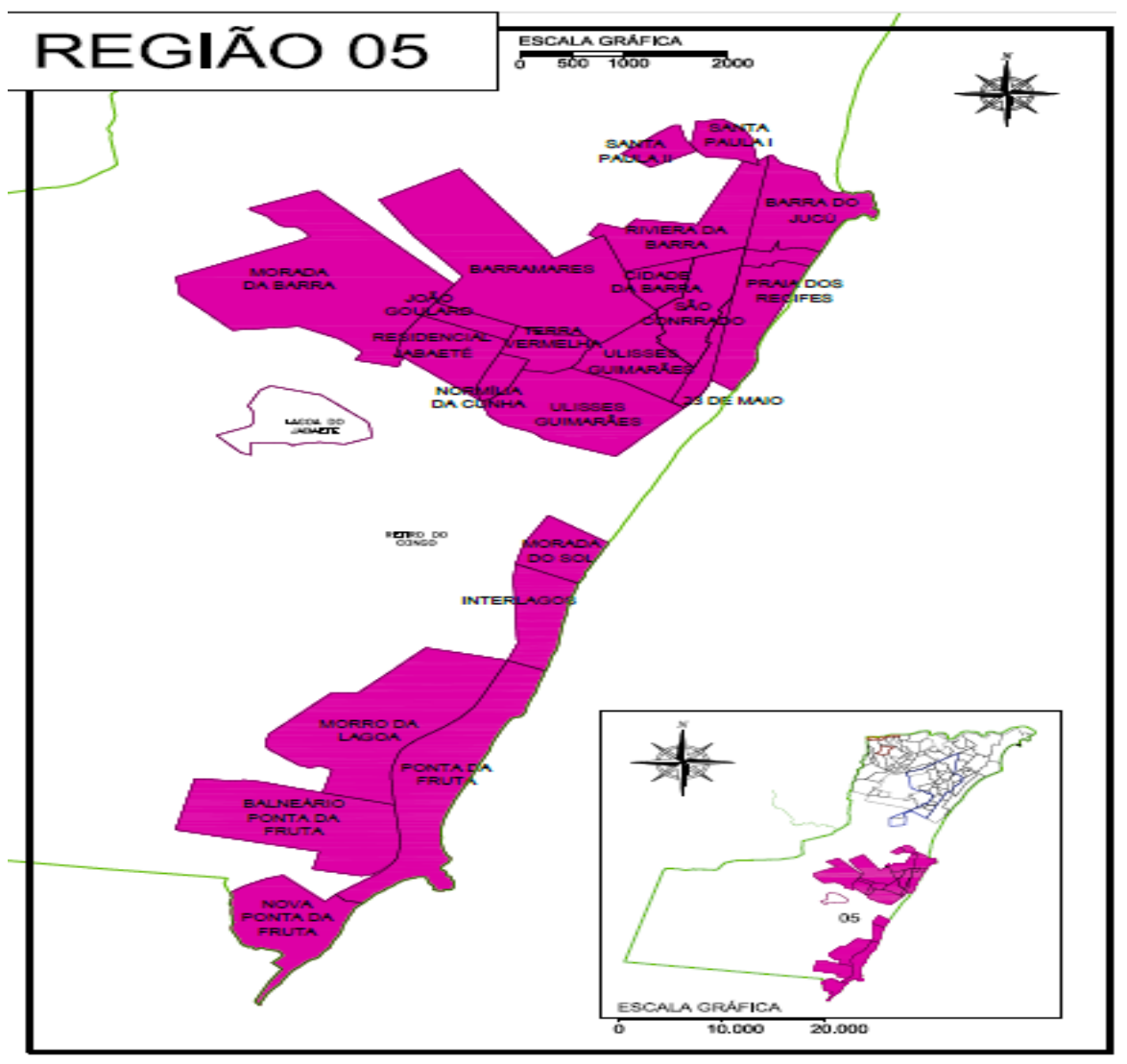

Fonte: Prefeitura Municipal de Vila Velha. SEMPLA - Secretaria Municipal de Planejamento. Vila Velha em Dados. Perfil socioeconômico por bairros. Vila Velha. 2013. p. 6. www.vilavelha.es.gov.br.

Embora o município tenha estabelecido seu primeiro Plano Diretor Urbano (PDU) em 1979 como Projeto de Lei do Perímetro Urbano ${ }^{11}$, ampliado na Lei n. ${ }^{\circ} 1.980 / 82^{12}$, observamos que as leis urbanísticas nas prerrogativas destes instrumentos legais até a primeira década do século XXI, não conseguiram impedir a expansão desordenada do município, bem como não frearam a ocupação em áreas impróprias para habitação. Fenômeno já estabelecido e que passou a tomar vulto em maiores dimensão e visibilidade a partir do início de 1960. A expansão urbana seguiu um traçado dissociado de uma política de desenvolvimento urbano ativa, na prática de um processo de planejamento abrangente ao município em toda sua territorialidade.

A continuidade das ocupações periféricas carentes de forma desordenada, que avançavam no espaço urbano do município, constituía um desafio de difícil enfrentamento. A ausência de mecanismos públicos que pudessem garantir uma maior racionalidade na forma de

11 IJSN. Plano Diretor Urbano de Vila Velha. Projeto de Lei do Perímetro Urbano. 1979. www.ijsn.es.gov.br. 12 Lei n. ${ }^{\circ}$ 1.980/82 dispõe sobre o parcelamento, regulação, controle e uso do solo no município de Vila VelhaES. Revogada pela Lei No . 4.575/2007 que instituiu o Plano Diretor Municipal (PDM), vigor em janeiro de 2008. www.legislacaoonline.com.br/vilavelha/leis 
ocupação do espaço urbano, principalmente em áreas periféricas, impulsionou o movimento das ocupações irregulares por populações menos favorecidas e que necessitavam de um lugar para se fixar e habitar.

\section{Aglomerado de Terra Vermelha: a representação da segregação socioespacial}

O Aglomerado de Terra Vermelha, localizado ha $15 \mathrm{~km}$ do centro do município de Vila Velha, retrata um cenário onde a trilogia desigualdade, segregação e exclusão constitui a representação maior no conjunto da prática excludente que marca as particularidades das periferias e da pobreza no Brasil. As ocupações tiveram início a partir de meados dos anos 80 e se alargaram em espaços impróprios (em grande maioria), irregulares e localizadas em áreas de risco, em condições de precariedade habitacional, de infraestrutura e de acesso a serviços públicos. Até o censo de 2010 estava constituído por um conjunto de 13 bairros, que se expandiram na faixa terrestre ao lado da Rodovia do Sol. ${ }^{13}$

A dinâmica que se estabeleceu nesta periferia da cidade de Vila Velha, entrelaçou invasões, loteamentos ilegais, loteamentos particulares, incentivo de ocupações de áreas pela via do poder público, loteamento público para a implantação de habitações de interesse social, prevalecendo o movimento de invasões e a prática da autoconstrução em áreas improprias para moradia. As habitações precárias, que se estabeleciam neste território, passaram a abrigar famílias com total desamparo social, constituídas inicialmente por grupos carentes vindos de outras periferias de Vila Velha e da Grande Vitória e migrantes vindos do interior capixaba, do norte de Minas Gerais, de regiões periféricas do Rio de Janeiro, do norte deste mesmo estado e do sul da Bahia. Uma população constituída por uma grande maioria de famílias jovens, com baixo nível de escolaridade e sem formação profissional.

O início dos anos 90, época que marca a grande explosão da expansão das ocupações em Terra Vermelha, o padrão desordenado que invadia e se espalhava na região já ganhava grandes proporções agravando a situação de precariedade. A falta de infraestrutura (de energia elétrica, de água encanada, rede de esgoto, calçamento) aliada à ausência de atendimento de serviços públicos conduziu os moradores a um movimento de reivindicações em favor de moradias e de melhorias locais, que se manteve em permanente luta por melhores condições de

13 ES-060 - conhecida como Rodovia do Sol, é uma rodovia radial que liga Vitória ao sul do Espírito Santo, passando pelo litoral sul capixaba. www.der.es.gov.br. 
sobrevivência no aglomerado. ${ }^{14}$ Em 2000 o IBGE registrou um total de 29.566 habitantes distribuídos em 11 bairros, apresentando relevantes situações de precariedade habitacional e de vida, classificados como assentamentos subnormais ${ }^{15}$ (LORENA et all, 2016),

Tendo por referência resultados de nossa pesquisa empírica, observamos que as histórias de vida apontadas pelos moradores locais são muito parecidas, desde aqueles mais antigos que chegaram a partir do início da ocupação, aos que foram se instalando em períodos posteriores. A realidade é a mesma, não tinham lugar para morar, chegaram a Vitória em busca de trabalho e melhores condições de vida, precisavam de um abrigo fixo, não tinham emprego e as condições de moradias anteriores em outras periferias da região metropolitana de Vitória eram extremamente precárias e pagavam aluguel. Aliada a estas situações todos revelam que não tinham dificuldades em conseguir e demarcar um lote para fazer um barraco e ter uma moradia ali naquele lugar. Apontamos a grande dificuldade enfrentada pelos moradores em conseguir um trabalho que possibilitasse uma moradia legal, sendo obrigados a procurar abrigo em lugares distantes dos centros urbanos, sem infraestrutura, mas que em contrapartida, era um lugar para morar sem custos com habitação.

As oportunidades abertas pelo desenvolvimento industrial da cidade representaram um novo horizonte, fato que impulsionou o movimento migratório para a região da Grande Vitória. Por outro lado, as dificuldades existentes no interior da sociedade urbana mudaram a realidade desejada por essas pessoas, que, em grande maioria, passaram a viver nas periferias em estado de pobreza absoluta e de segregação, juntamente com outros grupos, na mesma situação de precariedade.

O acelerado processo de diferenciação socioespacial e o agravamento da problemática urbana revelados com maior intensidade a partir de 1980 elevaram consideravelmente o índice de vulnerabilidade social nas cidades brasileiras, concentrado de forma intensa nas periferias. Na região da Grande Vitória, a pobreza, associada ao movimento acelerado da urbanização desordenada, contribuiu de forma decisiva para a magnitude dos problemas sociourbanos. $\mathrm{O}$ município de Vila Velha, embora já com uma periferia consolidada e com uma ampla parcela

14 O movimento comunitário em Terra Vermelha tem suas bases na luta pela moradia, Ver: SARTÓRIO, Fernando Domingos Vieira. Uma geopolítica do urbano: grande Terra Vermelha, região metropolitana da Grande VitóriaES. UFES, 2015. Monografia.

15 Para o IBGE, o conceito de subnormal se aplica a uma classificação de setores censitários para dimensionar as condições socioespaciais, evidenciando as características mais específicas dos aglomerados e não de pessoas, a categoria "situação precária", é empregada para medir especificidades de espaços considerados precários, não mencionando particularidades dos ocupantes. IBGE, Metodologia do Censo Demográfico 2000. Rio de Janeiro, 2003 (Série Relatórios Metodológicos/Setor Especial de Aglomerado Subnormal. v. 25, 6.3.1.3. Disponível em: www.ibge.gov.br. 
de população em estado de pobreza e carência social, passou a assistir a reprodução e a multiplicação desses problemas na região de Terra Vermelha, que aliou à violência as precárias condições de sobrevivência. Esse cenário evidencia também a ausência de instrumentos institucionais e administrativos adequados para fazer frente à dimensão do problema social estabelecido nas periferias da cidade.

A ocupação e a expansão do Aglomerado ocorreram tendo como característica uma dinâmica social e ocupacional nas fronteiras da informalidade, demarcando o caráter especifico da pobreza que se alarga nas periferias metropolitanas brasileiras. O aglomerado, mesmo sendo atingido por algumas iniciativas de políticas públicas sociais e urbanas municipais, mantém em evidência os riscos e as vulnerabilidades sociais que se agravam e não perdem a expressão no contexto da problemática urbana municipal. Nas ocupações que se expandem no aglomerado, a precariedade e a vulnerabilidade das condições de vida e socioambientais são muito expressivas, aliadas à deficiência de serviços básicos para a sobrevivência e às condições inadequadas de habitabilidade ${ }^{16}$.

A manutenção das condições insatisfatórias de sobrevivência se inscreve na ausência de direitos à cidadania e à falta de políticas públicas mais direcionadas e imediatas, que possam enfrentar o crescimento desordenado que adentra as periferias de forma acelerada reproduzindo e multiplicando a situação de pobreza em grande plenitude. As intervenções do poder público municipal no Aglomerado de Terra Vermelha, ocorridas a partir do final dos anos 90, não foram expressivas, permanecendo o elevado déficit de infraestrutura urbana, de saneamento básico e demais serviços, inclusive de transporte coletivo (IPES, 2001).

A naturalização desta forma vulnerável de moradia, consolidada em ocupações periféricas irregulares, sem as mínimas condições de habitabilidade, marca o espaço urbano das cidades brasileiras num amplo processo de desamparo socioeconômico e civil, que de acordo com Kowarik (2003, p. 78) "[...] conduzem ao que pode ser designado de processo de descidadanização", que no entendimento do autor ultrapassa os limites da privatização da cidadania, gerando um processo mais perverso de privatizações de direitos civis.

Em Terra Vermelha, esse processo se reproduz nas formas de ocupação que se aceleraram nos anos 90 prosseguindo na década seguinte com o mesmo desordenamento

\footnotetext{
16 Vulnerabilidades, termo usado no sentido conceitual, setores socialmente desprovidos na situação de carências e ausência de condições para atingir as necessidades mínimas de sobrevivência. Ver: ABRAMOVAY, Miriam (Coord.). Juventude, violência e vulnerabilidade social na América Latina: desafios para políticas públicas. Brasília: UNESCO, BID, 2002. KOWARICK, Lúcio. Sobre a vulnerabilidade socioeconômica e civil. Estados Unidos, França e Brasil. RBCS. Vol. 18 nº 51 fevereiro, 2003.
} 
espacial, adentrando a região em ampla expansão, afastando-se cada vez mais do núcleo central do aglomerado. Na medida em que esse processo intensificava uma pobreza maior de forma rápida, também se registra o distanciamento e a ausência do poder público, contribuindo para que nestes cinturões de pobreza absoluta se multipliquem as vulnerabilidades sociais, as irregularidades urbanas e as situações de violência, alargando os limites da desigualdade social e da miserabilidade urbana.

Neste movimento de ocupação, situamos, conforme informações dos moradores em nossa pesquisa de campo e fontes da COMASSES (Comissão de Assentamentos do Espírito santo), ações iniciais do poder municipal, voltadas para a construção de moradias sociais atendendo famílias carentes desabrigadas e que viviam em áreas de grande vulnerabilidade, sujeitas a riscos constantes de alagamentos em tempos de chuvas. Iniciativas que tomaram forma em caráter parcial sem um projeto maior de realojamento de famílias carentes. Aliada a esta iniciativa, emergem alternativas de moradia para outras camadas de população na mesma condição de pobreza, sem perspectivas de habitabilidade na cidade formal e que buscavam abrigo nas periferias com facilidades de ocupação irregular. Paiva; Gonçalves (2005, p. 1166) apontam que:

Ao visualizar documentos que se encontravam no COMASSES, relatórios, registros de lotes desenhados, percebeu-se que houve sim um planejamento para o bairro que deu origem ao nome da região que hoje é o Bairro Terra Vermelha, o próprio estilo de casas, moduladas com placas de cimento, de conjunto habitacional, refletem esta realidade, todavia, a grande maioria dos loteamentos, é fruto de invasões e alvo de estratégias políticas.

As formas irregulares pelas quais o aglomerado se constituiu, expandiu e se consolidou ocorreram com ausência de atendimento de ações públicas, ausência que se manteve durante um longo período, fato que promoveu a multiplicação das situações de insegurança, precariedades e de insalubridades, consolidando também alternativas informais e irregulares na busca de minimizar as dificuldades locais. Alternativas que, mesmo com a posterior intervenção pública, permaneceram vigentes, na medida em que também permaneceu a expansão desordenada e irregular com a proliferação de moradias precárias e insalubres. Fato que reflete a própria permanência da reprodução da pobreza, com os mesmos mecanismos tradicionais interligados num processo persistente que toma vulto, fugindo do controle do poder público (OLIVEIRA, 2014).

De uma forma geral, este tipo de expansão irregular nas periferias das cidades, caracterizando a informalidade do espaço urbano, de acordo com (ROLNIK (2006, p. 200) 
representa um “[...] modelo dominante de territorialização dos pobres nas cidades brasileiras, a consolidação desses assentamentos é progressiva, eternamente incompleta e totalmente dependente de uma ação discricionária do poder público". Nas engrenagens da desigualdade social e da exclusão territorial, esta realidade priva uma ampla parcela da população das oportunidades do desenvolvimento econômico e humano que a cidade oferece a seus habitantes, conduzindo à negação dos direitos à cidadania e reproduz condições para a composição de espaços urbanos onde não se fortalecem princípios de urbanidade. A falta de urbanidade no sentido físico corresponde à condição de (sub) cidadania no sentido político, transformando esses territórios fragmentados e apartados em laboratórios de enfraquecimento da cidadania, alargando, neste cenário as margens da criminalidade. Rolnik (1997). Situação que coloca as cidades nas fronteiras do regular e irregular, entre o espaço legal, urbanizado, dotado de infraestrutura e atendimento público e o ilegal, pobre, precário e segregado. Fronteiras onde transita a grande maioria do trabalhador urbano brasileiro, coexistindo com um cotidiano entre os entrelaces das relações licitas e ilícitas no universo complexo das multifacetadas redes que dominam essas relações (TELLES, 2010). Maricato (2003, p.15) considera que essa porção irregular da cidade marcada pela desigualdade e pela segregação socioespacial "[...] parece fornecer, frequentemente, uma base para que a exclusão se realize em sua globalidade".

Esta dualidade "cidade legal e ilegal, regular e irregular" que constitui o eixo determinante da problemática urbana brasileira, foge dos princípios legais dos direitos à cidade, que de acordo com o Estatuto da Cidade, compreende dentre outras questões, garantia do direito à cidade sustentável "[...] entendido como o direito à terra urbana, à moradia, ao saneamento ambiental, à infraestrutura urbana, ao transporte e serviços públicos, ao trabalho e ao lazer, para as presentes e futuras gerações (ESTATUTO DA CIDADE, 2001, p. 13) ${ }^{17}$. No Brasil prevalece um grande distanciamento entre a realidade e o reconhecimento legal dos direitos à cidade. Dados do IBGE, expressam este cenário.

O censo de 2010 apontou para o Espírito Santo uma população de 3.514 .952 pessoas, deste total, 48,0\% estava concentrada na Região Metropolita da Grande Vitória. Nesta região, o município de Vila Velha, desde os anos de 1990, apresenta a maior concentração populacional, com 24,0\% em 200 e um pequeno aumento para 24,6 \% em 2010 (Censos, 2000/2010). Nesta concentração destacamos o Aglomerado de Terra Vermelha.

17 Estatuto da Cidade (Lei. N.10.257/2001) Ver: SAULE JÚNIOR, Nelson; ROLNIK, Raquel Estatuto da Cidade: novos horizontes para a reforma urbana. São Paulo, Pólis, 2001. (Cadernos Pólis, 4). 
Tabela 1 - Município de Vila Velha - ES: População do Aglomerado de Terra Vermelha - 2010

\begin{tabular}{|l|r|}
\hline \multicolumn{1}{|c|}{ BAIRROS } & POPULAÇÃO \\
\hline Barramares & 12.405 \\
\hline Ulisses Guimarães & 7.271 \\
\hline Morada da Barra & 4.940 \\
\hline Riviera da Barra & 3.445 \\
\hline São Conrado & 2.981 \\
\hline Terra Vermelha & 2.847 \\
\hline Jabaete & 2517 \\
\hline João Goulart & 2.367 \\
\hline Santa Paula II & 2.153 \\
\hline Cidade da Barra & 2.085 \\
\hline Normília & 1.355 \\
\hline Vinte e Três de Maio & 1.254 \\
\hline Santa Paula I & 539 \\
\hline TOTAL & $\mathbf{4 6 . 1 5 9}$ \\
\hline
\end{tabular}

Fonte: IBGE. Censo Demográfico, 2010. http://www.cidades.ibge.gov.br.

De acordo com o censo de 2000, o Aglomerado de Terra Vermelha abrigava 29 mil habitantes (IBGE, 2000). Em 2010, o censo registra um total de 46.159 mil habitantes, distribuída nos 13 bairros, conforme demonstrado na tabela acima.

Os bairros se entrelaçam num labirinto de ruelas sem pavimentação, que se multiplicam no território ocupado, retratando uma situação de grande pobreza, insalubridade e condições inadequadas de vida. Poucas vias pavimentadas convergem para os bairros, sendo a Avenida Comercial, a principal via que atravessa o aglomerado, concentrando os serviços e o comércio local. Como marca da ocupação, predomina a elevada densidade de moradias inacabadas e pequenas com espaço entre 1 até 4 cômodos, com banheiro a parte, no quintal e várias construções tipo 'puxadinho' que se espalham nos terrenos, abrigando famílias de no mínimo 5 pessoas. $\mathrm{O}$ arruamento irregular completa a paisagem da autoconstrução na configuração do espaço construído, seguindo as possibilidades de seus moradores.

Com o estigma da pobreza e da irregularidade, os aglomerados caracterizados como "favelas" e ou "Aglomerados subnormais", são vistos como os concentradores dos problemas da cidade, sejam espaciais, sociais e ou ambientais, uma vez que concentram também a 
precariedade de vida urbana com toda sua dimensão. Realidade expressa por uma moradora, que reside no local desde o início da ocupação.

Aqui tem de tudo, casa boa, barracos na beira do valão sem esgoto, amontoados de casinhas nestas ruas, com um monte de cômodos no quintal também sem esgoto, casas de conjunto - que o povo invade, são despejados e invade de novo. Tem muita gente boa que trabalha muito pra sustentar os filhos, tem criança na rua, tem violência, droga, pontos de traficantes [...] tem o posto da polícia, a polícia faz ronda por aqui, mas não adianta [...] quando chove a gente fica alagado [...] no início era muito pior, hoje tá bom [...] mas a gente vive aqui. ${ }^{18}$

A pesquisa de campo demonstrou também que no Aglomerado de Terra Vermelha, a fusão entre a instabilidade de vida e as limitações pessoais, envolvendo fragilidade social, econômica, urbana e também familiar, aliadas à falta de escolaridade e de perspectivas futuras produz e reforça condições que agravam situações de delinquência e da violência local. Aqui, situamos a incidência da violência em dimensão maior com indicador da desigualdade, da ruptura do tecido social e dos $\operatorname{conflitos}^{19}$. A grande maioria dos jovens abandona a escola entre 16 e 17 anos de idade, os meninos com um percentual mais elevado. Vários fatores internos e externos à escola contribuem para o abandono escolar. Em nossa pesquisa a preocupação maior foi detectar os principais motivos que levam os adolescentes locais a abandonar a escola.

Foram apontadas: necessidade de trabalhar para ajudar a família, desinteresse nos estudos pela dificuldade de aprendizagem, pela falta de interesse individual, a não valorização da educação escolarizada, as oportunidades de ganhar dinheiro no mundo do tráfico de droga, desestruturação familiar e a gravidez precoce. Quanto à necessidade de trabalhar, as oportunidades situam-se nos núcleos das atividades informais e, inseridos nestes núcleos, os jovens perdem o estimulo para retomar os estudos. A grande maioria não permanece na escola para iniciar o ensino médio, sendo muito expressivo o número de adolescentes que não conclui essa etapa escolar. Registrando também a agravante situação dos alunos que não conseguem concluir o ensino fundamental, onde a grande maioria encontra-se com idade superior à adequada e muitos em situação de repetência escolar ${ }^{20}$.

18 Depoimento Sra. Ronilda Leandro, 55 anos, separada do marido, mãe de três filho, avó de 4 netos, empregada doméstica, chefe de domicilio. Residente do Aglomerado de Terra Vermelha, desde meados dos anos 80.

19 Ver. ZALUAR, Alba. Abordagem ecológica e os paradoxos da cidade. Revista de Antropologia, São Paulo, USP, 2010, v. 53, nº.2, p. 611-643.

20 As escolas pesquisadas relataram a situação da evasão escolar no contexto da realidade social local, sem dados estatísticos. 
O mundo do trabalho para os jovens e adolescentes é complexo, onde prevalecem condições de carências materiais e falta de perspectivas futuras. No universo das ocupações informais de trabalho, não é difícil o envolvimento com atividades relacionadas ao tráfico de drogas, colocando o jovem fora da escola e em articulações de alto risco social. No caso das meninas é muito expressiva a gravidez na adolescência, sendo muito comuns adolescentes mães solteiras que começam a trabalhar como balconistas em lojas comerciais, supermercados, faxineiras, manicures, etc.

Quanto ao cotidiano das crianças e dos jovens, a pesquisa não identificou um espaço de articulações de lazer apropriado para esses grupos e ou, uma instituição ou um lugar de integração social além da escola, o espaço público para o lazer é a rua. A ausência de praças e de parques e a inexistência de atividades culturais colocam a rua e seus guetos como eixo na identificação de encontros e de reprodução de sociabilidade, representando o espaço livre, aberto e ao mesmo tempo emblemático, tratando-se dos riscos e das vulnerabilidades. A maior referência até o ensino fundamental, são as escolas, que promovem atividades extra-sala, em projetos de escola aberta, como uma forma de interação social entre família, escola e comunidade.

Fenômenos como a existência de grupos dominantes locais com perfis diferenciados, grupos de gangues e o desenvolvimento das relações estabelecidas no mundo do uso e do tráfico de drogas e que se desenvolvem em grandes proporções, fogem do controle do poder público, em função, principalmente da ineficiência institucional relativa à segurança pública. Zanotelli (2004, p. 17), observa:

A delinquência é em parte tolerada, mesmo porque nenhuma sociedade funciona com o controle total de sua população, zonas de tolerância são previstas. A invocação da lei para melhor reprimir parcela da população pode fazer parte de uma regulação social que de fato opera mais pelo laisser faire que por uma verdadeira política de proteção dos mais fragilizados socialmente.

Os grupos dominantes locais estabelecem relações de poder sob forma de ameaças "[...] além dessa difusão de um poder "arcaico" entre bandos e grupos que lutam pelo controle do poder nos bairros" [...] (id) alastrando inseguranças, principalmente entre jovens e adolescentes. Registramos o fato de que, em geral esses jovens não se deslocam para outras regiões fora dos núcleos pontuais dos bairros que compõem o aglomerado, limitando as 
condições de sociabilidade e de conhecimento além das fronteiras do território que habitam, e que produz e reproduz as representações da vida cotidiana local.

Situações de pobreza, de ausência de atividades culturais e de lazer, de carências sociais e pessoais e de violência, atravessam a vida das pessoas que ali habitam, intensificando os conflitos frente às mazelas sociais e a permanente ausência do Estado. Assim, a fragmentação sociourbana, espelhando características da desigualdade, principalmente nos espaços segregados das favelas, ganha expressão num cenário urbano caótico em meio a demandas de toda natureza e que possam garantir condições mínimas de vida.

Trabalhos realizados em âmbito acadêmico e público expressam a preocupação relativa à questão social urbana e relatam a realidade que predomina nas cidades brasileiras de pequeno, médio e grande porte, em uma linha explicativa onde;

[...] descrevem a forte relação entre a deteriorização urbana observada e seus impactos sobre as condições de vida das pessoas, reforçando a teoria de que não é apenas a pobreza que explica o problema da violência, mas uma série de fatores relacionados [...] No entanto, a magnitude no número de homicídios encontrada nas macrorregiões de mais baixo IQU está de acordo com autores que relacionam homicídios com precárias condições socioeconômicas (BASTOS, et.al. 2009, p. 11).

Nos aglomerados de grande pobreza, segregação e violência, em geral, as vítimas são jovens entre 14 e 21 anos, destacando-se o sexo masculino com o maior registro de casos atingidos. A ausência de oportunidades de integração social e de perspectivas pessoais limitam os laços de sociabilidade e cria alternativas para agrupamentos de gangs que se apropriam deste vazio, e também por:

[...] grupos de tráfico, que em muitos lugares, marca presença, ocupando um espaço deixado em aberto pelo poder público, constituindo referência para os jovens. [...] Além da falta de equipamentos nas comunidades, os jovens circulam em raio restrito, segregados nos seus bairros, não necessariamente exercendo direitos de cidadania social, como, o benefício do uso da cidade em que vivem (CASTRO; ABRAMOVAY, 2002, p. 157).

Constatamos que os jovens convivem cotidianamente com a violência, tendo a mesma uma representação natural no contexto local. Em geral o Aglomerado de Terra Vermelha apresenta um quadro de violência muito preocupante, permanecendo com infraestrutura, saneamento e transporte coletivo precários e ausência de equipamentos comunitários. Registrase a carência de creches e as escolas públicas são insuficientes para atender à demanda local, 
mantendo um grande déficit educacional na região, o que contribui para a fragilidade social. A segurança é ineficiente atuando num universo de grande complexidade e que exige uma ampla ação de políticas públicas voltadas a essa questão, integrando gestores públicos, polícia e sociedade civil.

É nesse contexto de extrema complexidade social que abordamos o município de Vila Velha, fortemente impactado, como os demais municípios da Região Metropolitana da Grande Vitória, pelo movimento contemporâneo de modernização capitalista, envolvendo dimensões econômicas, sociais, políticas e culturais na dinâmica do desenvolvimento desigual como marco no processo de desenvolvimento nacional.

\section{Considerações Finais}

No Brasil o desenvolvimento capitalista tem sido marcado expressivamente pelo elevado crescimento econômico e pelos efeitos de uma acelerada urbanização desigual e segregativa. $\mathrm{O}$ crescimento urbano desordenado fortalece e impulsiona o contínuo agravamento de inúmeros problemas das cidades que se intensificam, com relação intricada nas fragilidades socioeconômicas e nas políticas administrativas. A cidade de Vila Velha, foco de nossa pesquisa, é um exemplo clássico dessa realidade nacional, num quadro de distanciamento entre o centro e sua periferia, retratando as marcas da desigualdade social. O Aglomerado de Terra Vermelha com seu elevado grau de pobreza espelha as representações da degradação social, da fragilidade humana e da segregação no cenário urbano municipal, permanecendo como o lugar de expansão periférica precária e de abrigo para uma elevada parcela da classe trabalhadora municipal e de municípios vizinhos. Compreender alguns mecanismos na dinâmica da reprodução da desigualdade social nos conduz para uma maior percepção do diálogo estabelecido entre pobreza, segregação e exclusão, que entrelaça uma interface nos territórios periféricos das cidades, ultrapassando situações de desprovimento socioeconômico, atingindo um grau muito mais abrangente de privações.

As necessidades prioritárias demandadas no Aglomerado de Terra Vermelha e a complexidade socioespacial dos assentamentos subnormais são reconhecidas pelo poder público municipal. Entretanto, as políticas públicas implementadas a partir do final dos anos 90 não tiveram uma estratégia de integração e de desenvolvimento, nem formas definidas de ação na busca de alternativas que pudessem alcançar resultados a médio ou a longo prazo, e os problemas se avolumaram, fugindo do controle das ações públicas. 
As iniciativas mais recentes voltadas para implementar melhorias urbanas e atendimento público, embora contribuindo com o enfrentamento de dificuldades, não alcançam as necessidades de forma mais abrangente. Fica notável que os avanços são insuficientes na totalidade dos problemas que se apresentam e se reproduzem seguindo a própria dinâmica socioespacial do aglomerado, sem intervenções que possam promover uma reintegração social e a recuperação das condições de cidadania.

\section{Referências}

BASTOS, Márcia de Jesus Rocha; PEREIRA, Jacira dos Anjos; SMARZARO, Dorian Chim et.al. (2009. Análise ecológica dos acidentes e da violência letal em Vitória, ES. Revista de Saúde Pública, São Paulo, v. 43, n. 1, p. 123-132. Disponível em: http://www.scielo.br. Acesso em: 5 de agosto de 2018.

BRASIL. Casa Civil. Estatuto da cidade. Lei N. 10.257 de 10 de julho de 2001. Regulamenta os arts. 182 e 183 da Constituição Federal, estabelece diretrizes gerais da política urbana e dá outras providências. Disponível em: http://legislacao.planalto.gov.br. Acesso em 12 de agosto de 2018.

. CONGRESSO NACIONAL. Comissão Mista Especial. Relatório Final da Comissão Mista Especial para estudos de soluções sobre as desigualdades sociais, regionais e pobreza no Brasil. Brasília. 1999. Disponível em: http://www.senado.gov.br. Acesso em: 18 de outubro de 2018.

BRESSER-PEREIRA, Luiz Carlos. Crescimento e desenvolvimento econômico. Rio de Janeiro: Fundação Getúlio Vargas, 2008.

CARVALH0, Edemir de. Cidades brasileiras, crescimento e desigualdade social. Org. \& Demo, n.3, 2002. p. 45-54. Disponível em: http://www.marilia.unesp.br. Acesso em: 13 de setembro de 2018.

CASTEL, Robert. "Armadilhas da exclusão". In: WANDERLEY, Mariangela Belfiore; BÓGUS, Lúcia; YAZBEK, Maria Carmelita. (orgs.). Desigualdades e a questão social. $3^{\mathrm{a}}$ ed. São Paulo: EDUC, 2010.p. 21-54.

CASTRO, Mary Garcia; ABRAMOVAY, Miriam. Jovens em situação de pobreza, vulnerabilidades sociais e violências. Cadernos de Pesquisa, n. 116, 2002, p. 143 -176. Disponível em: http://www.scielo.br. Acesso em: 28 de agosto de 2018.

DAVIS, Mike. Planeta Favela. Tradução: Beatriz Medina. São Paulo: Boitempo, 2006.

DRAIBE, Sonia. Rumos e metamorfoses: Estado e industrialização no Brasil 1930-1960. Rio de Janeiro: Paz e Terra, 2004. 
ESPÍRITO SANTO: SECRETARIA DO ESTADO DE PLANEJAMENTO. Instituto de Pesquisa Econômica e Social - IPES. Região Metropolitana da Grande Vitória. Dinâmica urbana da década de 90. Vitória. 2001.

GARCIA, Ronaldo Coutinho. Iniquidade Social no Brasil: uma aproximação e uma tentativa de dimensionamento. Ministério do Planejamento, Orçamento e Gestão. IPEA Brasília. 2003. Disponível em: http://www.ipea.gov.br. Acesso em: 10 de setembro de 2018.

GIDDENS, Anthony. Sociologia: uma breve porém crítica introdutória. Rio de Janeiro Zahar, 1984.e

GOUVÊA, Ronaldo Guimarães. A questão metropolitana no Brasil. Rio de Janeiro: FGV. 2005.

IVO, Anete Brito Leal. Políticas sociais, pobreza e trabalho: dilemas do bem-estar em países de capitalismo periférico. Bahia Análise \& Dados, v. 17, n. 4, 2008. p. 1121-1133. Disponível em: http://www.ipc-ndp.org/publications. Acesso em: 26 de outubro de 2018.

IBGE. Instituto Brasileiro de Geografia e Estatística. Censo Demográfico de 2000. Disponível em: http://www.ibge.gov.br/home/estatistica/populacao/censo2000. Acesso em: 14 de setembro de 2018.

Censo Demográfico de 2010. Disponível em: http://www.ibge.gov.br/home/estatistica/populacao/censo2010. Acesso em: 18 de setembro de 2018.

KOWARICK, Lúcio. Sobre a vulnerabilidade socioeconômica e civil. Estados Unidos, França e Brasil. RBCS. Vol. 18 nº 51 fevereiro, 2003. p. 61 -85. Disponível em: http://www.scielo.br. Acesso em 20 de fevereiro 2018.

LORENA, Rodrigo Borredo et all. Caracterização de Assentamentos Precários por meio de Zonas Especiais de Iteresse Social na Região Metropolitana da Grande Vitória, Espírito Santo. In: MORAIS, Maria da Piedade; KRAUSE, Cleandro; LIMA Neto, Vicente Correia (Orgs.). Caracterização e tipologia de assentamentos precários: estudos de caso Brasileiros. Brasília, Ipea, 2016. Cap.11, p. 377-409.

MARICATO, E. Metrópole, legislação e desigualdade. Estudos Avançados, v. 48, n. 17, 2003. p. 151-167. Disponível em: www.scielo.br. Acesso em maio de 2018.

ROLNIK, Raquel. Prefácio. In: ALFONSIN, Betânia de Moraes (Org.). Direito à Moradia: instrumentos e experiências de regulação fundiária nas cidades brasileiras. Rio de Janeiro: Observatório de Políticas Urbanas: IPPUR: FASE, 1997.

A construção de uma política fundiária e de planejamento urbano para o país - avanços e desafios. políticas sociais. IPEA. Acompanhamento e análise. 12/fev. 2006. p. 199-210. Disponível em: www.ipea.gov.br/politicas_sociais/ensaios. Acesso em 13 de março 2018.

OLIVEIRA, Ueber José de. Resgatando memórias de quem faz história: a ocupação e transformação da Região da Grande Terra Vermelha-ES. Revista Urutágua. DCS/UEM. n. 30, 
2014. p. 42-58. Disponível em: http://www.camacarinoticias.com.br.. Acesso em: 12 de novembro de 2018.

OLIVEN, Ruben George. Urbanização e mudança social no Brasil [online]. Rio de Janeiro: Centro Edelstein, 2010. Available from SciELO Books. http://www.books.scielo.org.

PAIVA, Davi Rocha; GONÇALVES, Cyntia Silva. "Impacto sócio-ambiental na Região da Grande Terra Vermelha Vila Velha - ES". In: X ENCONTRO DE GEÓGRAFOS DA AMÉRICA LATINA. Anais do X Encontro de Geógrafos da América Latina. São Paulo: USP. 2005. p. 11162-11179. Disponível em: http://www.observatoriogeograficoamericalatina.org. Acesso em: 16 de janeiro 2018.

PREFEITURA MUNICIPAL DE VILA VELHA. Secretaria Municipal de Planejamento SEMPLA/PMV. Planejamento Orçamento e Gestão. Vila Velha em Dados. Perfil socioeconômico por bairros/Vila Velha. ES. 2013. Disponível em: http://www.vilavelha.es.gov.br. Acesso em: 8 de outubro de 2018.

SEN, Amartya K. Desenvolvimento com liberdade. São Paulo: Cia das Letras. 2000.

SIQUEIRA, Maria da Penha Smarzaro."Os Grandes Projetos Industriais: desenvolvimento econômico e contradições urbanas". In: SIQUEIRA, Maria da Penha Smarzaro (org.). Desenvolvimento brasileiro: alternativos e contradições. Vitória: Grafitusa, 2010. p. 13- 38.

O porto de Vitória: expansão e modernização. 1950-1993. Vitória:

CODESA, 1994.

SILVA, Maria Ozanira da Silva e. Pobreza, desigualdade e política pública: caracterizando e problematizando a realidade brasileira. Revista Katálysis, Florianóplois, v. 13, n. 2, jul./dez. 2010.

SOUZA, J. A construção social da subcidadania: para uma Sociologia Política da modernidade periférica. Belo Horizonte: UFMG. 2003

SPOSATI, Aldaíza de Oliveira. Mapa da exclusão/inclusão social na cidade de São Paulo. São Paulo: EDUC. 1996.

Vida urbana e gestão da pobreza. São Paulo: Cortez. 1998.

TELLES, Vera da Silva. A cidade entre as fronteiras do legal e ilegal. Belo Horizonte: Argumentum, 2010.

WANDERLEY, Luiz Eduardo W. "A questão social no contex to da globalização: o caso latinoamericano e o caribenho". In: WANDERLEY, Mariangela Belfiore; BOGUS, Lúcia; YAZBEK, Maria Carmelita (orgs.). Desigualdade e a questão social. 3.ed. São Paulo: EDUC. 2010. p. 55-166.

ZANOTELLI, Cláudio Luiz. "Fragmentações sócio-espaciais e criminalidade violenta: o caso de Terra Vermelha - Aglomeração de Vitória - ES". Encontro Estadual de Geógrafos do 
Fronteiras: Revista de História

Aglomerados periféricos: a expressão da tradicional pobreza e da segregação nas cidades brasileiras

Maria da Penha Smarzaro Siqueira

Espírito Santo. Vitória. 2004. p. 97-113. Disponível em: http://www.revistahumanas.org. Acesso em: 10 de maio de 2018.

Recebido em: 14/05/2019

Aprovado em: 30/10/2019 